\title{
Multisite Implementation and Evaluation of 12-Month Standard Dialectical Behavior Therapy in a Public Community Setting
}

Flynn, Daniel; Kells, Mary; Joyce, Mary; Corcoran, Paul; Hurley, Justina; Gillespie, Conall; Suarez, Catalina; Swales, Michaela; Arensman, Ella

\section{Journal of Personality Disorders}

DOI:

10.1521/pedi_2018_32_402

Published: 01/06/2020

Peer reviewed version

Cyswllt i'r cyhoeddiad / Link to publication

Dyfyniad o'r fersiwn a gyhoeddwyd / Citation for published version (APA):

Flynn, D., Kells, M., Joyce, M., Corcoran, P., Hurley, J., Gillespie, C., Suarez, C., Swales, M., \& Arensman, E. (2020). Multisite Implementation and Evaluation of 12-Month Standard Dialectical Behavior Therapy in a Public Community Setting. Journal of Personality Disorders, 34(3), 377393. [402]. https://doi.org/10.1521/pedi_2018_32_402

\footnotetext{
Hawliau Cyffredinol / General rights

Copyright and moral rights for the publications made accessible in the public portal are retained by the authors and/or other copyright owners and it is a condition of accessing publications that users recognise and abide by the legal requirements associated with these rights. study or research.

download and print one copy of any publication from the public portal for the purpose of private

- You may not further distribute the material or use it for any profit-making activity or commercial gain

- You may freely distribute the URL identifying the publication in the public portal ?
}

Take down policy

If you believe that this document breaches copyright please contact us providing details, and we will remove access to the work immediately and investigate your claim. 
Multi-site implementation and evaluation of 12 month standard dialectical behaviour therapy in a public community setting

\begin{abstract}
Dialectical behaviour therapy (DBT) is an effective intervention for treating adults with emotional and behavioural dysregulation. The National DBT Project, Ireland was established in 2013 to coordinate the implementation of DBT across public community mental health settings at a national level. This study describes the implementation and evaluation of DBT across multiple independent sites in adult mental health services (AMHS). The Consolidated Framework for Implementation Research was used to guide this national implementation where barriers and facilitators to DBT implementation were considered. Nine AMHS teams completed DBT training and delivered the 12 month standard programme. One hundred and ninety-six adults with borderline personality disorder participated in the programme and outcome measures were recorded at four time-points. Significant reductions on outcome measures including frequency of self-harm and suicidal ideation were observed. This study highlights that DBT can be successfully implemented in community mental health settings as part of a coordinated implementation.
\end{abstract}


A large body of evidence demonstrates the efficacy of dialectical behaviour therapy (DBT) for treating individuals with borderline personality disorder (BPD). More than a dozen randomised controlled trials of DBT have been conducted at multiple independent sites (e.g. Linehan et al., 2006; McMain et al., 2009). Participation in DBT has been associated with reductions in suicidal behaviour, suicidal ideation, BPD symptoms, hopelessness and depression. It has also been shown to reduce health service utilisation and/or inpatient psychiatric days. In addition, a systematic review of randomised studies has shown DBT to be significantly better than treatment-as-usual (Stoffers et al., 2012).

While these studies demonstrate the efficacy of DBT for treating BPD in controlled environments, the effectiveness of DBT when implemented in routine clinical settings needs to be considered. Comtois, Elwood, Holdcraft, Smith, and Simpson (2007) conducted the first effectiveness study of DBT in a community mental health setting. Their study and subsequent effectiveness studies (e.g. Flynn et al., 2017; Pasieczny \& Connor, 2011; Prendergast \& McCausland, 2007; Stiglmayr et al. 2014) have reported positive outcomes for DBT when delivered in community settings.

In 2006, a government policy framework for mental health services in Ireland recommended DBT as a treatment for individuals with BPD (Government of Ireland, 2006). Coinciding with this, a national registry of self-harm facilitated increasing awareness of high rates of self-harm following the publication of annual reports derived from data gathered at hospital emergency departments across the country. These annual reports of self-harm rates provided evidence in support of the need for evidence-based interventions such as DBT in Ireland. However, challenges regarding securing of funding for individual team training and awareness of how best to establish DBT in community services existed (Flynn, Kells \& Joyce, 2018). With this in mind, a proposal was put forward to a National Office for Suicide Prevention (established to coordinate suicide and self-harm prevention activities in Ireland) to coordinate DBT training at a national level in the Irish public health service (Flynn, Kells \& Joyce, 2018). This proposal was successful and the National DBT Project, Ireland was established in 2013. The funding included training for two cohorts of eight teams in both adult and child/adolescent mental health services over a 
two year period. Funding was also allocated for a team to coordinate and support the multi-site implementation and evaluation.

In having a coordinated approach to implementation, the National DBT Project team could consider known facilitators and barriers in an attempt to maximise successful DBT implementation in community mental health settings. Previously identified barriers to DBT implementation include lack of financial support, absence of management buy-in, lack of prioritisation of DBT as a treatment option, inadequate planning for programme delivery, competing therapeutic priorities, staff attrition and insufficient protected time for DBT (Carmel, Rose \& Fruzetti, 2013; Swales, Taylor \& Hibbs, 2012; Swenson, Torrey \& Koerner, 2002). Factors reported to facilitate successful DBT implementation include: organisational support (including funding and time to deliver the intervention); supervision; team cohesion, skill and leadership; and observation of positive clinical outcomes (Ditty, Landes, Doyle \& Beidas, 2015; Swales et al., 2012).

The National DBT Project was the first to coordinate DBT training at a national level and to develop a protocol to consider known implementation facilitators and barriers. It was also the first national multisite study of DBT in community services. This paper provides an overview of the implementation framework that was used to guide this coordinated implementation of DBT. Previously identified barriers and facilitators which were addressed as part of this initiative are outlined. A secondary aim of this study was to conduct a comprehensive evaluation on the effectiveness of the DBT programmes established across multiple independent sites as part of the national coordinated implementation. This paper pertains solely to the implementation and evaluation of DBT in adult mental health services (AMHS) as part of this coordinated effort. 


\section{Method}

\section{Implementation}

The Consolidated Framework for Implementation Research (CFIR; Damschroder et al., 2009) was used as a guiding framework for this coordinated implementation of DBT. This framework was applicable for use in the National DBT Project as a whole which included implementation of DBT in both adult and child/adolescent mental health services (the implementation and evaluation of DBT in child/adolescent mental health services is reported elsewhere; Flynn, Kells, Joyce, Corcoran, Gillespie et al., 2018). The 'Process' construct of the CFIR involves planning, engaging, executing and evaluating; these stages were followed in an iterative manner throughout the project and are illustrated in figure 1. Insert figure 1 here.

Figure 1 - Consolidated Framework for Implementation Research - ‘Process’ Construct In following the various steps that are part of the 'Process' construct, previously identified barriers and facilitators to DBT implementation could be given due consideration throughout the different stages of the project. A summary of barriers and facilitators and how they were addressed in this coordinated implementation initiative is presented in table 1. 
Table 1 Management of barriers and facilitators to DBT implementation in the National DBT Project

\begin{tabular}{|c|c|c|}
\hline Barriers/Facilitators & Mitigated by: & Details on how barriers and facilitators were addressed \\
\hline \multicolumn{3}{|l|}{ Barriers } \\
\hline Lack of financial support & Centralised funding & Funding for training, supervision and resources through national coordinating office \\
\hline \multirow[t]{4}{*}{$\begin{array}{l}\text { Absence of } \\
\text { management buy-in }\end{array}$} & $\begin{array}{l}\text { Management sign off at } \\
\text { training application stage }\end{array}$ & $\begin{array}{l}\text { All application forms had to be countersigned by management in the DBT team's service } \\
\text { area to verify that: }\end{array}$ \\
\hline & & - Proposed DBT team would be released from clinical duties to attend intensive training \\
\hline & & $\begin{array}{l}\text { - Management would support local costs associated with training attendance (e.g. } \\
\text { travel, subsistence) }\end{array}$ \\
\hline & & $\begin{array}{l}\text { - Each DBT team member could dedicate } 1.5 \text { days per week for DBT implementation for } \\
\text { a minimum of two years }\end{array}$ \\
\hline $\begin{array}{l}\text { Lack of prioritisation of } \\
\text { DBT as a treatment }\end{array}$ & $\begin{array}{l}\text { Training application form; } \\
\text { Orientation meeting }\end{array}$ & $\begin{array}{l}\text { DBT teams were required to provide a rationale as to how and why DBT could be } \\
\text { implemented in their service area at training application stage; }\end{array}$ \\
\hline option & & $\begin{array}{l}\text { Prioritisation of DBT as a treatment option in the service area was discussed at } \\
\text { orientation meeting with all teams prior to training }\end{array}$ \\
\hline $\begin{array}{l}\text { Inadequate planning for } \\
\text { programme delivery }\end{array}$ & $\begin{array}{l}\text { Written documentation; } \\
\text { Orientation meeting; }\end{array}$ & $\begin{array}{l}\text { Written documentation about setting up a DBT programme and relevant reading lists } \\
\text { were circulated to all teams before training; }\end{array}$ \\
\hline & Individual team site visit & $\begin{array}{l}\text { Planning for programme delivery was discussed at orientation meeting and individual } \\
\text { site visits with all teams prior to training; }\end{array}$ \\
\hline $\begin{array}{l}\text { Competing therapeutic } \\
\text { priorities }\end{array}$ & Training application form & $\begin{array}{l}\text { All application forms had to be countersigned by management in the DBT team's service } \\
\text { area to verify that each DBT team member could dedicate } 1.5 \text { days per week to } \\
\text { prioritise working with this high-risk group }\end{array}$ \\
\hline Staff attrition & $\begin{array}{l}\text { Training application form; } \\
\text { Foundational training }\end{array}$ & $\begin{array}{l}\text { At training application stage, the team leader was required to verify that each DBT team } \\
\text { member would dedicate } 1.5 \text { days per week for DBT implementation for a minimum of } \\
\text { two years. Application forms were countersigned by management in the service area; } \\
\text { Foundational Training was provided through the coordinating office on an annual basis } \\
\text { to replenish teams with staff attrition }\end{array}$ \\
\hline
\end{tabular}


Insufficient protected Training application form time for DBT

Facilitators

Organisational support Coordinating team

Supervision

Expert supervision

Team cohesion, skill and

leadership

Team consult; Additional

training; Expert supervision

Observation of positive

Research evaluation

clinical outcomes
All application forms had to be countersigned by management in the DBT team's service area to verify that each DBT team member could dedicate 1.5 days per week for DBT implementation for a minimum of two years
Coordinating team including project coordinator, administrator, research support team to support teams in their implementation

Panel of international experts who would provide regular DBT supervision to all DBT teams

All teams were required to deliver all modes of treatment including weekly team consult;

Additional training (skills training workshop, DBT team leader training) was delivered by the treatment developer and expert trainers;

Expert DBT supervision was included for all DBT teams and was contingent on all modalities of DBT being delivered.

Comprehensive research evaluation of national implementation reported on clinical effectiveness of DBT for clients;

Findings from research evaluation would be disseminated through peer reviewed articles, conference presentations, annual reports;

Feedback would also be provided to each team on programme outcomes in their service 


\section{Selection and training of teams}

For the National DBT Project, the structure of DBT teams followed the recommendations of the UK licensed training provider of Intensive Training ${ }^{\mathrm{TM}}$ which specify that DBT teams must have a minimum of four clinicians and a maximum of ten ${ }^{1}$. Each team was required to either have a

clinical/forensic/counselling psychologist or a person with demonstrable graduate training in behaviour therapy.

Interested teams were invited to submit an application to the National DBT Project to attend training. Following a training application process, all applications were reviewed by a Steering Group committee. A number of criteria were considered for eligibility and prioritisation of training places as demand exceeded supply (Flynn, Kells \& Joyce, 2018). Teams that were successful in securing a training place undertook a 2-week Intensive Training ${ }^{\mathrm{TM}}$ in the period between December 2013 and May 2015 with a licensed training provider.

The training comprises 70 hours of face-to-face teaching in DBT that includes didactic instruction, group and individual exercises, accompanied by role-play demonstrations. Teams leave the first week of training with a comprehensive list of homework assignments that relate to setting up a DBT service and further developing their skills in delivering the treatment. During the second week of training, teams present their service structures and individual cases, and receive feedback and consultation on how to further enhance their service delivery and therapeutic skills.

Two cohorts of training took place where eight teams (both adult and child/adolescent mental health teams) attended each event. Training for each cohort of teams was centralised in one location where two DBT trainers travelled to Ireland to deliver parts 1 and 2 of the training.

\section{Supervision}

\footnotetext{
${ }^{1}$ In 2013, recommendations by the licensed training provider allowed up to a maximum of ten members per DBT team. This was revised in 2015 and current training requirements allow a maximum of eight team members.
} 
Expert supervision was provided to all teams with 36 hours available to each team per year. Supervision was provided by internationally accredited model adherent DBT supervisors in Europe (United Kingdom, Norway and Austria) and the United States. Supervision was dependent on supervisor availability and was negotiated between the team and supervisors to meet the individual team requirements. Supervision typically involved input to the team consultation meeting via phone or video conference, discussion of clinical cases and a review of a proportion of audio-taped sessions with feedback from the supervisor. Whilst tapes were not rated for adherence, all supervisors were qualified to make adherence ratings and were able to provide feedback to teams to shape increasing adherence to the treatment. Early supervision sessions tended to focus on programme set-up issues with an increasing focus on therapeutic skills as the project progressed.

\section{Treatment}

Participants received the standard DBT programme as described by Linehan $(1993 a, b)$ which is delivered by a multidisciplinary team of mental health professionals. The DBT programme was delivered over a 12 month period and included weekly individual therapy sessions for each participant, weekly group skills training sessions, phone coaching and weekly consultation meetings for the therapists on the DBT team. Two therapists from the DBT team facilitated the skills group each week. Availability of phone coaching was dependent on individual therapists' personal limits. As per standard DBT programme rules, participants were informed that missing four consecutive group skills or individual therapy sessions would result in discharge from the programme for non-attendance.

\section{Participants}

All participants in the study were attending AMHS in community settings and were referred to the DBT programme by a member of the community mental health team. The inclusion criteria for participants in the study were: 
Diagnosis (or meet criteria for diagnosis) of Borderline Personality Disorder (DSM-IV-TR) or Emotionally Unstable Personality Disorder (EUPD; ICD-10)

A persistent pattern of self-harm or suicidal behaviour, with the most recent episode having occurred within the six months prior to being referred to the intervention

Participation in all modes of treatment and commitment to participate in the standard 12-month DBT programme

Participants' diagnosis of BPD/EUPD was independently made by the treating consultant psychiatrist on the community mental health team. Individuals with comorbid disorders and/or individuals on medication were permitted in the current study. The following exclusion criteria applied:

An active psychosis

Severe developmental delays, cognitive impairment or learning difficulties (that exceed the mild range)

Substance/ drug dependence, eating disorder or any other mental health issues/behaviour at such a level that it would impede their engaging with any of the modalities of DBT.

The analyses included 196 participants in this study. Table 2 summarises the sample characteristics for participants at baseline. 
Table 2 Sample characteristics of participants $(N=196)$

\begin{tabular}{|c|c|c|}
\hline Characteristics & $\mathrm{n}$ & $\%$ \\
\hline \multicolumn{3}{|l|}{ Gender } \\
\hline Female & 158 & 80.6 \\
\hline Male & 38 & 19.4 \\
\hline \multicolumn{3}{|l|}{ Age } \\
\hline $18-24$ years & 41 & 20.9 \\
\hline $25-34$ years & 57 & 29.1 \\
\hline $35-44$ years & 58 & 29.6 \\
\hline $45-54$ years & 35 & 17.9 \\
\hline $55-64$ years & 4 & 2.0 \\
\hline Did not specify & 1 & 0.5 \\
\hline \multicolumn{3}{|l|}{ Marital status } \\
\hline Single & 86 & 43.9 \\
\hline In a relationship & 45 & 23.0 \\
\hline Married & 36 & 18.4 \\
\hline Separated/Divorced & 27 & 13.8 \\
\hline Other & 2 & 1.0 \\
\hline \multicolumn{3}{|l|}{ Employment status } \\
\hline Full-time employment & 23 & 11.7 \\
\hline Part-time employment & 18 & 9.2 \\
\hline Student & 20 & 10.2 \\
\hline Retired & 3 & 1.5 \\
\hline Unemployed & 90 & 45.9 \\
\hline Other & 42 & 21.4 \\
\hline
\end{tabular}

The majority of participants were female, aged 25-44 years, single and unemployed.

\section{Outcome Measures}

Measures were selected and compiled based on the four treatment targets of DBT: reduction of life threatening behaviours, treatment interfering behaviours and quality of life interfering behaviours; and increase in skill utilisation (Koerner, 2011). A detailed overview of treatment targets and corresponding measurement variables for the overall study are reported elsewhere (Flynn, Kells, Joyce, Suarez \& Gillespie, 2018).

\section{Self-report measures}

Six self-report outcome measures were included in the current study: 
Borderline Symptom List (BSL-23; Bohus et al., 2007). The BSL-23 comprises 23 items measuring borderline-typical symptomatology. Respondents are asked to rate how much they suffered with a set of difficulties or problems in the course of the previous week ranging from 0 (Not at all) to 4 (Very strong). The BSL-23 has demonstrated high internal and test-retest reliability (Bohus et al., 2007). In the current study, the internal reliability for the BSL was .94 at baseline.

Beck Hopelessness Scale (BHS; Beck, Weissman, Lester \& Trexler, 1974). The BHS is a 20-item self-report measure which assesses key aspects of hopelessness. Items on the BHS are marked as true or false with scores ranging from 0 to 20, where higher scores indicating greater feelings of hopelessness. In the current study, the internal reliability for the BHS was .89 at baseline.

Beck Depression Inventory (BDI-II; Beck, Steer \& Brown, 1996). The BDI-II is a 21-item self-report questionnaire, which assesses symptoms ranging from not present (0) to severe (3) as indicators of the severity of depression. The BDI-II has demonstrated good internal consistency and test-retest reliability and validity across different populations and cultural groups. The internal reliability of the BDI-II in the current study was .91 at baseline.

Questionnaire for Suicidal Ideation (QSI). The QSI is a 6-item measure developed to assess frequency of suicidal ideation in the past week. Each item was rated on scale of 0 (Not at all) to 4 (Daily or more). In the current study, the internal reliability of the QSI was .91 at baseline.

The State and Trait Anger Inventory (STAXI-2; Spielberger, 1988). The STAXI-2 integrates the State-Trait Anger scale and the Anger Expression (AX) Scale and is comprised of five independent subscales. : State Anger, Trait Anger, Anger-in, Anger-out, and Anger Control. A sixth scale involves an arithmetic combination of the Anger-in, Anger-out, and Anger Control subscales to provide a general index of the frequency with which anger is expressed. The STAXI has demonstrated good reliability and validity. The internal reliability for the STAXI-2 scales in the present study were as follows: State Anger .96; Trait Anger .90; Anger Expression Out .82; Anger Expression In .70; Anger Control Out .82; Anger Control In 
.82. As trait anger and anger expression out are the most pertinent subscales for this study population, these will be the focus of the reported data.

DBT Ways of Coping Checklist (DBT-WCCL; Neacsiu, Rizvi, Vitaliano, Lynch \& Linehan, 2010). The DBTWCCL is a 59-item measure consisting of two scales, the DBT Skills Use scale and the Dysfunctional Coping scale, which assess skills use and dysfunctional coping to manage difficult situations in the past month. Items of the DBT-WCCL are rated on a scale of 0 (Never Used) to 3 (Regularly Used). The DBTWCCL has demonstrated good psychometric properties (Neacsiu et al., 2010). The internal reliability for the two scales in the present study was .93 (DBT Skills Use) and .81 (Dysfunctional Coping).

\section{$\underline{\text { Health Service Utilisation }}$}

DBT therapists on each team completed a client record form developed by the research team to measure health service utilisation and resource use (Flynn, Kells, Joyce, Suarez \& Gillespie, 2018). DBT therapists collated data about their clients including frequency of self-harm, emergency department (E.D.) visits, and number of inpatient admissions at each time-point. This data was extracted from the clinical file for each participant by the DBT therapist. At each data collection time-point, the relevant timeframe was: baseline (T1) referring to the 6 months prior to the intervention; T2 referring to the first 6 months of the intervention; T3 referring to the second 6 months of the intervention and T4 referring to the 6 months following programme completion.

\section{Therapist Rated Assessment}

DBT therapists also completed measures regarding patient functioning at each time-point (Flynn, Kells, Joyce, Suarez \& Gillespie, 2018). Reporting of the Global Assessment of Functioning (GAF) will be focused on for the purpose of this study.

\section{Procedure}


Data was collected from participants and DBT therapists at 6-month intervals across an 18-month timeframe. There were four time-points for data collection with DBT participants: baseline (T1), midway through intervention (T2), end of intervention (T3), and six months post-intervention (T4). Baseline referred to when participants had completed pre-treatment and prior to starting the group skills training. Members of the DBT research team visited the sites at each time-point for data collection. At baseline, DBT clients were briefed about the study and informed written consent was obtained where clients indicated their willingness to participate in the research study. A DBT therapist was present for the group data collection session so that they could provide appropriate clinical input in the event of a participant becoming distressed. For the follow-up data collection (T4), participants either attended a group data collection session with a member of the research team, completed measures with their DBT therapist or measures were posted directly to participants.

\section{Statistical analysis}

All self-report outcome measures were quantitative and were summarised by their mean and standard deviation. For each self-report outcome measure, multilevel linear mixed-effects regression models were used to estimate the mean at baseline (T1) and the mean change from baseline to each follow-up (T2, T3 and T4). Mixed-effects models use all available data at each time-point rather than the data from individuals assessed at all times. We included a random intercept in the models for the individual participants and for the participating sites. These intercepts adjust for random heterogeneity in each outcome measure between subjects and between study sites.

Exact McNemar's tests and McNemar-Bowker tests were used to explore change in the proportion of the sample that were self-harming, and the frequency of self-harm, from T1 to T3 and T3 to T4. Reliable and clinically significant change was calculated using Jacobson's criterion b (Jacobson, Roberts, Berns \& 
McGlinchey, 1999). Data were analysed using Stata Version 13.1 for IBM SPSS Statistics 23.0 for Windows. 


\section{Results}

\section{Implementation outcomes}

Nine Adult Mental Health Service (AMHS) teams completed DBT training; four in Cohort 1 and five in Cohort 2. Sixty-nine therapists in total were trained across the nine teams. Each of the teams comprised of four to ten multi-disciplinary staff members including psychiatrists, psychologists, nurses, social workers, addiction counsellors and occupational therapists. Treatment commenced with patients in the weeks following Intensive Training Part 1. All teams began full programme delivery (all modes of treatment) within 6 months of Intensive Training Part 1 and prior to attending Part 2. All teams continued to offer DBT in their service two years following completion of Intensive Training Part 1.

\section{DBT Programme Outcomes}

Of the 196 participants, 109 participants completed the programme. Of the 87 participants who did not complete the programme, $78 \%(n=68)$ dropped out (4-miss rule); $13 \%(n=11)$ moved to another treatment; $6 \%(n=5)$ felt sufficiently recovered to stop treatment; and $3 \%(n=3)$ left the programme for other reasons including physical health issues or having passed away from natural causes.

There was missing data for participants at some time-points. Reasons for missing data included incomplete measures by participants or their DBT therapist, participants being absent during the group data collection session or failure to administer measures within the recommended 2-week timeframe.

\section{Self-report Measures}

The means and standard deviation of each of the six outcome measures (measuring eight constructs) at each time-point are detailed in table 3. 
Table 3 Outcome measure means (M) and standard deviations (SD) at each study time-point.

\begin{tabular}{l|cccc}
\hline & $T 1 M(S D)$ & $T 2 M(S D)$ & $T 3 M(S D)$ & $T 4 M(S D)$ \\
Variable & $n=188$ & $n=124$ & $n=101$ & $n=87$ \\
\hline Borderline Symptoms & $51.24(20.86)$ & $37.70(23.00)$ & $31.55(24.77)$ & $28.89(23.34)$ \\
Hopelessness & $13.20(5.25)$ & $9.72(6.34)$ & $7.65(6.36)$ & $7.51(6.16)$ \\
Depression & $36.36(12.42)$ & $25.60(14.39)$ & $20.67(15.22)$ & $18.30(15.00)$ \\
Suicidal Ideation & $9.29(7.06)$ & $6.20(6.85)$ & $4.93(6.00)$ & $4.27(5.72)$ \\
Dysfunctional Coping & $41.40(9.20)$ & $35.08(10.47)$ & $32.23(12.37)$ & $31.62(12.25)$ \\
DBT Skill Use & $51.68(20.20)$ & $70.94(20.64)$ & $77.57(20.90)$ & $80.17(19.98)$ \\
Anger & & & & \\
\multicolumn{1}{l}{ Trait Anger } & $55.73(12.86)$ & $49.33(11.04)$ & $46.78(10.69)$ & $44.90(8.78)$ \\
$\quad$ Anger Exp. Out & $53.63(12.57)$ & $49.68(10.63)$ & $47.23(9.79)$ & $45.95(7.90)$ \\
\hline
\end{tabular}

Based on the information presented in table 3, there was evidence of decreases in borderline symptoms, hopelessness, depression, suicidal ideation, dysfunctional coping, trait anger and anger expression out, and evidence of an increase in DBT skill use. This was confirmed by the linear mixedeffects models as detailed in table 4. 
Table 4 Outcome measure estimated baseline means (M) and changes at subsequent time-points.

\begin{tabular}{|c|c|c|c|c|}
\hline Variable & $\begin{array}{l}\text { Estimate T1 } \\
\mathrm{M}(95 \% \mathrm{Cl})\end{array}$ & $\begin{array}{l}\text { Change at T2 } \\
M(95 \% \mathrm{Cl})\end{array}$ & $\begin{array}{l}\text { Change at T3 } \\
\mathrm{M}(95 \% \mathrm{Cl})\end{array}$ & $\begin{array}{l}\text { Change at T4 } \\
M(95 \% \mathrm{Cl})\end{array}$ \\
\hline Borderline Symptoms & $51.67(47.70,55.64)$ & $-13.76(-17.83,-9.68)^{*}$ & $-21.23(-25.64,-16.83)^{*}$ & $-22.73(-27.36,-18.09)^{*}$ \\
\hline Hopelessness & $13.27(12.39,14.14)$ & $-3.58(-4.63,-2.53) *$ & $-5.67(-6.79,-4.55)^{*}$ & $-5.70(-6.89,-4.51)^{*}$ \\
\hline Depression & $36.63(34.31,38.94)$ & $-10.70(-13.10,-8.29)^{*}$ & $-16.46(-19.05,-13.88) *$ & $-17.69(-20.42,-14.95)^{*}$ \\
\hline Suicidal Ideation & $9.28(8.25,10.32)$ & $-2.93(-4.02,-1.84) *$ & $-4.66(-5.83,-3.49)^{*}$ & $-5.06(-6.30,-3.82)^{*}$ \\
\hline Dysfunctional Coping & $41.68(39.84,43.51)$ & $-6.47(-8.45,-4.48)^{*}$ & $-9.49(-11.62,-7.37)^{*}$ & $-9.60(-11.86,-7.34)^{*}$ \\
\hline DBT Skill Use & $51.25(48.33,54.18)$ & $+19.73(16.23,23.22)^{*}$ & $+25.73(21.97,29.48) *$ & $28.39(24.42,32.36)^{*}$ \\
\hline \multicolumn{5}{|l|}{ Anger } \\
\hline Trait Anger & $55.95(54.22,57.68)$ & $-7.00(-8.74,-5.26)^{*}$ & $-8.47(-10.35,-6.60)^{*}$ & $-10.58(-12.58,-8.57)^{*}$ \\
\hline Anger Exp. Out & $53.69(52.10,55.29)$ & $-4.11(-5.83,-2.39) *$ & $-6.09(-7.96,-4.22)^{*}$ & $-7.48(-9.53,-5.43)^{*}$ \\
\hline
\end{tabular}

Note: Changes at each time-point are relative to the baseline; $95 \% \mathrm{Cl}=95 \%$ confidence interval 
There were significant changes from T1 to T3 on all outcome measures. Improvements were maintained at follow-up. The use of standardised scales for depression and hopelessness allows for categorisation of clinical severity level which in turn can inform clinically meaningful change for participants. For example, mean depression scores that were in the 'severe' clinical range at T1 decreased to the 'moderate' range at T2, and were at the lower end of the 'moderate' range at T3. Scores further reduced and were in the 'mild' clinical range at follow-up (T4). Similarly for hopelessness, participants were at the high end of the 'moderate' range at $\mathrm{T} 1$, reducing but still in the 'moderate' range at $\mathrm{T} 2$, and further reduced to the high end of the 'mild' range at T3. These scores were maintained at T4.

\section{Clinically Significant Change}

In order to determine the degree of clinically significant change, Jacobson's criterion $b$ was calculated for participants who completed the programme. The BSL was chosen as the main outcome variable. $41 \%(n=40)$ of programme completers fulfilled this criteria and were considered recovered in a clinically relevant way.

\section{Therapist Rated Assessment}

The means and standard deviation of the Global Assessment of Functioning (GAF) were calculated for programme completers at each time-point. The mean score at T1 ( $M=44.5, S D$ $=17.2)$ was in the 'serious symptoms' range. At $T 2$, the mean score $(M=58.3, S D=13.8)$ moved to the 'moderate symptoms' range. Scores moved to the 'mild symptoms' range at $\mathrm{T} 3(\mathrm{M}=66.9, \mathrm{SD}=13.1)$ and at $\mathrm{T} 4(\mathrm{M}=67.8, \mathrm{SD}=11.1)$. At $\mathrm{T} 1,17.2 \%$ of programme completers had scores above 60 . This increased to $47.4 \%$ at T2, $71.5 \%$ at T3 and $77.4 \%$ at T4. 
Self-harm Behaviour and Frequency

Completed datasets from therapists at T1 and T3 were available for 92 of 109 participants who completed the programme, and for 80 participants at T4. The presence and frequency of self-harm as reported by therapists is outlined in table 5 . 
Table 5 Self-harm presence and frequency at each time-point for 92 programme completers

\begin{tabular}{|c|c|c|c|c|c|c|c|c|}
\hline \multirow[b]{3}{*}{ Variable } & & \multicolumn{3}{|c|}{$n=92$} & & \multicolumn{2}{|c|}{$n=80$} & \multirow[b]{3}{*}{$p$} \\
\hline & & $\mathrm{T} 1$ & vs & T3 & & T3 & T4 & \\
\hline & & $n(\%)$ & & $n(\%)$ & $p$ & $n(\%)$ & $n(\%)$ & \\
\hline SH Present & Yes & $81(88)$ & & $44(48)$ & $<.001$ & $37(46)$ & $20(25)$ & $<.001$ \\
\hline \multirow[t]{4}{*}{ SH Frequency: } & Not at all & $11(12)$ & & $48(52)$ & $<.001$ & $43(54)$ & $60(75)$ & $<.05$ \\
\hline & Rarely & $22(24)$ & & $26(28)$ & & $23(29)$ & $13(16)$ & \\
\hline & Occasionally & $18(20)$ & & $10(11)$ & & 7 (9) & $4(5)$ & \\
\hline & Often/Most of the time & $38(41)$ & & $8(9)$ & & $5(6)$ & $1(1)$ & \\
\hline
\end{tabular}

Exact McNemar's tests determined that there was a significant decrease in the proportion of participants self-harming from T1 to T3. A further significant decrease was noted from T3 to T4. McNemar-Bowker tests determined a significant decrease in the frequency of self-harm behaviour from $\mathrm{T} 1$ to $\mathrm{T} 3$ and a further reduction from T3 to T4. 
Health Service Utilisation

Descriptive statistics for Emergency Department (E.D.) visits, Acute Inpatient Admissions and corresponding number of hospital days at each time-point are presented in table 6 .

Table 6 Health service utilisation at four time-points for 109 participants who completed the programme

\begin{tabular}{|c|c|c|c|c|c|}
\hline Variable & & $\begin{array}{c}T 1 \\
(n=108)\end{array}$ & $\begin{array}{c}T 2 \\
(n= \\
103)\end{array}$ & $\begin{array}{c}\text { T3 } \\
(n=96)\end{array}$ & $\begin{array}{c}T 4 \\
(n=90)\end{array}$ \\
\hline $\begin{array}{l}\text { Total No. Emergency } \\
\text { Department (E.D.) Visits }\end{array}$ & & 90 & 22 & 15 & 10 \\
\hline $\begin{array}{l}\text { Total No. Acute Inpatient } \\
\text { Admissions }\end{array}$ & & 57 & 19 & 12 & 8 \\
\hline Total No. Inpatient Bed Days & & 1058 & 128 & 120 & 107 \\
\hline \multirow[t]{3}{*}{ No. ppt.s with: } & O E.D. visits & 51 & 86 & 81 & 80 \\
\hline & 1 E.D. visit & 27 & 14 & 13 & 10 \\
\hline & $>1$ E.D. visit & 25 & 3 & 1 & 0 \\
\hline \multirow[t]{3}{*}{ No. ppt.s with: } & 0 Admissions & 60 & 86 & 80 & 79 \\
\hline & 1 Admission & 29 & 9 & 12 & 8 \\
\hline & $>1$ Admission & 12 & 4 & 0 & 0 \\
\hline \multirow[t]{4}{*}{ No. ppt.s with: } & 0 Bed Days & 60 & 86 & 80 & 79 \\
\hline & 1-7 Bed Days & 18 & 6 & 5 & 4 \\
\hline & 8-28 Bed Days & 9 & 3 & 4 & 1 \\
\hline & >28 Bed Days & 11 & 2 & 1 & 2 \\
\hline
\end{tabular}

As can be seen in table 6, there was a decrease in the total number of E.D. visits from T1 to T3 (83\%), and a further decrease at T4. A notable decrease in the number of acute inpatient admissions (79\%) and corresponding bed days (89\%) was observed from T1 to T3, with further decreases at T4. 


\section{Discussion}

DBT programmes were successfully implemented in AMHS in nine areas across Ireland as part of this national coordinated implementation effort. Significant improvements on clinical measures were observed for participants and these gains were maintained or further improved at 6 months following programme completion. Substantial reductions in health service utilisation including inpatient admissions and emergency department visits were also observed.

At two years following completion of Intensive Training Part 1, all nine teams continued to offer DBT in their service. While staff attrition occurred across some sites, teams availed of further training opportunities to replenish staff. Staff attrition was foreseen as a potential implementation barrier by the coordinating team. Foundational Training was therefore incorporated into the implementation plan at the outset of the project to mitigate this barrier. These training opportunities to manage staff attrition were provided on an annual basis through the coordinating office. This gave teams the opportunity to continue to offer or expand DBT in their service and may in part account for team success and sustainability at two years post training.

A review of existing implementation studies regarding DBT guided efforts to manage potential barriers to successful programme implementation (Flynn, Kells \& Joyce, 2018). A series of steps were followed to account for barriers to implementation including; having centralised funding, a training application process, and orientation meetings with both DBT teams and area management teams. The employment of a coordinating team to administer and manage DBT training for the teams in this project was an attempt to facilitate successful implementation. Training was centrally planned, delivered by a licensed training provider, and support and guidance was provided to therapists for the implementation. All modes of 
treatment were delivered and all teams were provided with supervision by internationally accredited model adherent DBT supervisors. As a result of incorporating these factors, therapists were supported maximally to deliver the model. Despite success however, implementation can still be challenging. Although attempts were made to account for previously identified facilitators and barriers to implementation, new challenges (e.g. lack of mandate for implementation) arose in this national coordinated effort which needed proactive management. While these challenges are reported in detail elsewhere (Flynn et al., in preparation), the authors highlight the importance of DBT champions and health service managers working together to facilitate successful implementation.

The effectiveness of the DBT programmes which were established across multiple independent sites as part of the national coordinated implementation was also explored. The findings from the current study corroborate those of previous studies where significant improvements were found when evaluating DBT in real-world settings (Flynn et al., 2017; Pasieczny \& Connor, 2011; Stiglmayr et al. 2014). The reporting of follow-up data in this study expands on previous research where long term benefits of the intervention are demonstrated. In addition to statistically significant change, this study also reports that $41 \%$ of participants were considered recovered in a clinically meaningful way. These findings are comparable to other studies (e.g. Bohus et al., 2004) which report clinically significant change for participants.

A strength of this coordinated implementation of DBT was the availability of expert supervision for teams by internationally accredited model adherent DBT supervisors. It is recognised that supervision is fundamental in enhancing therapists' motivation, competence consolidation, adherence to the model, and ultimately sustainability of DBT programmes (Fruzzetti, Waltz \& Linehan, 1997). While there was some variation in the 
quantity of the supervision resource utilised across the nine sites, this did not appear to impact on outcomes for participants. While it is acknowledged that financial constraints, availability of expert DBT supervisors, and scheduling and logistical constraints of linking with supervisors in other jurisdictions and time zones can pose significant barriers to effectively engaging in and benefitting from expert supervision, it would be useful for future research to consider the relationship between quantity of supervision and client outcomes.

The administration of self-report measures to participants by an independent research team rather than the treating clinician attempted to reduce potential response bias. The coordinating research team also attempted to ensure that rigorous data collection procedures were adhered to by sending reminders to participants and therapists about upcoming data collection time-points, and preparing for and conducting data collection at the multiple sites. However, a limitation of this study is that self-harm behaviour and health service utilisation was measured through therapist completed forms rather than research scrutiny of clinical files.

There is a lack of consistency in the use of outcome measures across DBT studies which restricts the opportunity to explore and compare outcomes of DBT internationally. This study is unique in matching outcome measures to treatment targets whereby it was ensured that each treatment target was specifically evaluated (Flynn, Kells, Joyce, Suarez, Gillespie, 2018). It is hoped that future research on DBT might consider the battery of measures administered in this study for future evaluations. This would facilitate consideration of potential international and cultural differences in DBT research.

Given the financial burden and practical constraints of adherence coding, it was not feasible to obtain adherence ratings for therapists who participated in this study. Adherence rating is time intensive and requires significant financial investment to conduct. As there 
were a large number of therapists in this study which was conducted in a public community health setting, it was therefore not financially or practically possible to obtain adherence ratings for all 69 therapists. There were also practical constraints with regard to transfer of audio taped sessions outside of the jurisdiction within which this study was conducted. This highlights a need for the Irish public health service to review protocols and policies which would enable future research to capture these data.

One of the challenges of working in a publicly funded mental health system is that clinicians have a responsibility to treat every individual who presents to their service. While there are alternative evidence-based interventions for adult BPD populations (e.g. Schema Therapy, Mentalisation Based Therapy, Transference-Focused Psychotherapy), none were consistently available across multiple sites to act as a comparison group for this study. In an ideal scenario, comparison across interventions would be preferable and this is an area that warrants further study. However, there is value in comparing the results of the current study with those of effectiveness studies conducted internationally on DBT.

While the results reported here show a substantial reduction in health service utilisation over the course of the intervention, this data also contributes to a study which involves a comprehensive economic evaluation to assess the cost-effectiveness of DBT versus treatment-as-usual for adults with BPD. An Incremental Cost Effectiveness Ratio (ICER) will be calculated comparing the relative costs and outcomes. Given the comprehensive nature of the outlined analysis, details of the economic evaluation will be reported in a separate paper.

\section{Conclusion}

The results of the current study demonstrate that an intervention which has proven efficacy in randomised controlled trials can also be applied to real-world environments and achieve 
positive outcomes for participants. These results also lend support to the assertion that DBT can be implemented in a publicly funded national mental health system through considered planning and evaluation in a culture that is open to and supports continuous learning.

\section{Acknowledgements}

We would like to thank the DBT therapists at each of the nine study sites for facilitating and contributing to this study. We also wish to thank all DBT participants at the nine sites for contributing data to this study. This work was supported by funding from the National Office for Suicide Prevention in the Health Service Executive, Ireland. 


\section{References}

Beck, A.T., Weissman, A., Lester, D., \& Trexler, L. (1974). The measurement of pessimism: The Hopelessness Scale. Journal of Consulting and Clinical Psychology, 42(6), 861- 865.

Beck, A.T., Steer, R.A., \& Brown, G.K. (1996). Manual for the Beck Depression Inventory-II. San Antonio, TX: Psychological Corporation.

Bohus, M., Haaf, B., Simms, T., Limberger, M. F., Schmahl, C., Unckel, C., ... \& Linehan, M. M. (2004). Effectiveness of inpatient dialectical behavioral therapy for borderline personality disorder: a controlled trial. Behaviour research and therapy, 42(5), 487499.

Bohus, M., Limberger, M.F., Frank, U., Chapman, A.L., Kühler, T., \& Stieglitz R-D. (2007). Psychometric Properties of the Borderline Symptom List (BSL), Psychopathology, 40, 126-132.

Carmel, A., Rose, M. L., \& Fruzzetti, A. E. (2014). Barriers and solutions to implementing dialectical behaviour therapy in a public behavioural health system. Administration and Policy in Mental Health and Mental Health Services Research, 41(5), 608-614.

Comtois, K., Elwood, L., Holdraft, L., Smith, W., \& Simpson, T. (2007). Effectiveness of dialectical behaviour therapy in a community mental health centre. Cognitive and Behavioural Practice, 14, 406-414.

Damschroder, L. J., Aron, D. C., Keith, R. E., Kirsh, S. R., Alexander, J. A., \& Lowery, J. C. (2009). Fostering implementation of health services research findings into practice: a consolidated framework for advancing implementation science. Implementation science, 4(1), 50 .

Ditty, M. S., Landes, S. J., Doyle, A., \& Beidas, R. S. (2015). It takes a village: A mixed method analysis of inner setting variables and dialectical behavior therapy implementation. 
Administration and Policy in Mental Health and Mental Health Services Research, 42(6), 672-681.

Flynn, D., Kells, M. \& Joyce, M. (2018). Implementation in national systems: DBT in an Irish context. In M. Swales (Ed.), The Oxford handbook of dialectical behaviour therapy.

Flynn, D., Kells, M., Joyce, M., Corcoran, P., Gillespie, C., Suarez, C.,...Arensman, E. (2018). Innovations in Practice: Dialectical behaviour therapy for adolescents: multi-site implementation and evaluation of a 16-week programme in a public community mental health setting. Manuscript submitted for publication.

Flynn, D., Kells, M., Joyce, M., Corcoran, P., Gillespie, C., Suarez, C.,... Cotter, P. (2017). Standard 12 month dialectical behaviour therapy for adults with borderline personality disorder in a public community mental health setting. Borderline Personality Disorder and Emotion Dysregulation,4(19).

Flynn, D., Kells, M., Joyce, M., Suarez, C., \& Gillespie, C. (2018). Dialectical behaviour therapy for treating adults and adolescents with emotional and behavioural dysregulation: study protocol of a coordinated implementation in a publicly funded health service. BMC psychiatry, 18(1), 51.

Fruzzetti, A. E., Waltz, J. A. \& Linehan M.M. (1997). Supervision in dialectical behaviour therapy. In: Watkins, C. E. (editor). Handbook of psychotherapy supervision. New York: John Wiley \& Sons, Inc.. 84-100.

Government of Ireland (2006). A Vision for Change: Report of the Expert Group on Mental Health Policy. Dublin: Stationery Office.

Jacobson, N. S., Roberts, L. J., Berns, S. B., \& McGlinchey, J. B. (1999). Methods for defining and determining the clinical significance of treatment effects: description, application, and alternatives. Journal of consulting and clinical psychology, 67(3), 300. 
Koerner, K. (2011). Doing dialectical behavior therapy: A practical guide. Guilford Press.

Linehan, M. M. (1993a). Cognitive behavioural therapy of borderline personality disorder. New York: Guilford Press.

Linehan, M. M. (1993b). Skills training manual for treating borderline personality disorder. New York: Guilford Press.

Linehan, M., Comtois, K., Murray, A., Brown, M., Gallop, R., Heard, H., et al. (2006). Two year randomised controlled trial and follow-up of dialectical behaviour therapy vs therapy by experts for suicidal behaviours and borderline personality disorder. Archives of General Psychiatry, 63, 757-767.

McMain, S., Links, P., Gnam, W., Wuidmond, T., Cardish, R., Korman L.,et al., (2009). A randomised trial of dialectical behaviour therapy versus general psychiatric management for borderline personality disorder. American Journal of Psychiatry, 166, 1365-1374.

Neacsiu, A. D., Rizvi, S. L., Vitaliano, P. P., Lynch, T. R., \& Linehan, M. M. (2010). The dialectical behavior therapy ways of coping checklist: development and psychometric properties. Journal of clinical psychology, 66(6), 563-582.

Pasieczny, N., \& Connor, J. (2011). The effectiveness of dialectical behaviour therapy in routine public mental health settings: an Australian controlled trial. Behaviour Research and Therapy, 49, 4-10.

Prendergast, N., \& McCausland, J. (2007). Dialectical behaviour therapy: a 12 month collaborative program in a local community setting. Behaviour Change, 24(1), 24-35. Spielberger CD. Manual for the State-Trait Anger Expression Inventory (STAXI-2). Odessa, FL: Psychological Assessment Resources; 1988. 
StigImayr, C., Stecher-Mohr, J., Wagner, T., Meißner, J., Spretz, D., Steffens, C., ... \& Renneberg, B. (2014). Effectiveness of dialectic behavioral therapy in routine outpatient care: the Berlin Borderline Study. Borderline personality disorder and emotion dysregulation, 1(1), 20.

Stoffers, J.M., Vollm, B.A., Rucker, G., Timmer, A., Huband, N. \& Lieb, K. (2012).

Psychological therapies for people with borderline personality disorder. Cochrane Database of Systematic Reviews, 15(8).

Swales, M.A., Taylor, B., \& Hibbs, R.A. (2012). Implementing dialectical behaviour therapy: programme survival in routine healthcare settings'. Journal of Mental Health, 21(6), 548-555.

Swenson, C. R., Torrey, W. C., \& Koerner, K. (2002). Implementing dialectical behavior therapy. Psychiatric Services, 53(2), 171-178. 